D.O.I.: $10.3895 / \mathrm{S} 1808-04482007000100008$

\title{
AS POLÍTICAS INDUSTRIAIS E TECNOLÓGICAS E AS PEQUENAS E MÉDIAS EMPRESAS: INICIATIVAS NA HISTÓRIA RECENTE DA ECONOMIA BRASILEIRA
}

\section{THE INDUSTRIAL AND TECHNOLOGICAL POLITICS AND THE SMALL AND MEDIUM SIZE COMPANIES: INITIATIVES IN THE RECENT HISTORY OF THE BRAZILIAN ECONOMY}

\author{
João Amato Neto ${ }^{1}$ \\ ${ }^{1}$ Escola Politécnica da Universidade de São Paulo - EPUSP - São Paulo - Brasil \\ amato@usp.br
}

\begin{abstract}
Resumo
O objetivo deste artigo é realizar uma revisão crítica das várias propostas de política industrial e tecnológica desenvolvidas na história recente da economia brasileira e seus possíveis impactos em favor do desenvolvimento das pequenas e médias empresas (PMEs), enfatizando o aspecto da relação do poder público e o setor produtivo. O estudo destaca as iniciativas de cooperação produtiva como uma forma emergente de promoção de tais políticas. Quanto à metodologia, baseia-se em uma revisão de literatura com caráter exploratório e qualitativo.
\end{abstract}

Palavras-chave: política industrial, economia brasileira, pequenas e médias empresas, cooperação produtiva.

\section{Introdução}

Este artigo tem por objetivo apresentar e discutir as várias tentativas de estabelecimento de uma política industrial e tecnológica na história recente da economia brasileira, procurando, em especial, detectar seus principais efeitos no processo de desenvolvimento das pequenas e médias empresas. Busca salientar, também, os possíveis impactos de tais políticas em termos da promoção de redes de cooperação entre tais empresas e outros agentes econômico e sociais.

Cabe, inicialmente, explicitar o conceito de política industrial e tecnológica aqui empregado, a partir da contribuição de vários autores (RATTNER, 1985, 1981; CASAROTTO apud BIANCHI, 1995).

De uma maneira geral pode-se afirmar que as políticas industriais e tecnológicas envolvem o estabelecimento de projetos prioritários, por meio da adoção de medidas legais, 
administrativas e institucionais, constituindo-se em um poderoso instrumento para orientar a estrutura e a dinâmica da indústria, segundo paradigmas e trajetórias tecnológicas determinadas. Referem-se, portanto, a um conjunto de ações públicas orientadas a direcionar e controlar o processo de transformação estrutural de uma economia. Por seu turno, as políticas industriais locais. Relacionam-se, fundamentalmente, a um conjunto de ações de networking, ou seja, são ações voltadas para a construção de uma rede de configurações entre atores, que participam do desenvolvimento do processo produtivo em uma relação de ação coletiva. Referem-se, portanto, a um específico espaço territorial, podendo ser microregional, estadual ou macro-regional, de acordo com as específicas características das políticas ativadas e os resultados esperados (CASAROTTO FILHO e PIRES, 1999).

Segundo tais autores há, basicamente, dois mecanismos de elaboração e implementação de políticas locais:

$1^{\circ}$.Chamado de cima, refere-se a uma fase constitucional, em que se estabelecem os princípios gerais de aceitação dos caminhos de convergência entre os atores, estabelecendo também o tipo de processo decisório a ser adotado para as escolhas coletivas.

$2^{\circ}$.Requer capacidade por parte dos atores de promoverem ações de baixo, por meio de políticas que permitam a efetiva entrada e participação de todos .

No presente artigo, propõe-se focalizar os possíveis impactos das recentes políticas de Estado, tanto em nível nacional, como regional e local, em termos da promoção das pequenas e médias empresas. Neste sentido, inicia-se com uma breve retrospectiva dos vários Planos de Desenvolvimento e das Politicas Industriais praticados na economia brasileira nas últimas décadas Plano de Metas, Modelo de Substituição de Importações, Plano de Ação Estratégica do Governo (PAEG), Plano Nacional de Desenvolvimento (PND), Nova Política Industrial (nível macroeconômico).

\section{Breve retrospectiva das propostas de política Industrial}

Durante a década de 1970 no período conhecido como o "milagre econômico", a economia brasileira apresentou expressivas taxas de crescimento (de até 12\% ao ano). A partir do início dos anos 80 há uma reversão de tendências, quando a economia passou a registrar uma das mais sérias crises de toda a sua história. Os efeitos imediatos deste novo panorama traduziram-se por um baixo nível de investimentos produtivos em praticamente todos os setores da economia, com seus efeitos negativos sobre os níveis de renda e emprego, de uma forma geral.

Cabe lembrar, em tempo, o fato de que, por ser a economia brasileira marcada por uma industrialização tardia, ou seja, a indústria moderna se instalou no país já em plena fase do capitalismo monopolista mundial, há uma série de fatores históricos que bloqueiam um processo de desenvolvimento autônomo. Destaca-se, entre eles, a crescente interdependência das economias dos vários países dentro do processo de internacionalização globalizada, o que leva a uma situação de 
dificuldades competitivas por parte das empresas nacionais, principalmente das pequenas e médias, vis-à-vis às grandes empresas transnacionais, as quais apresentam, via-de-regra, melhores condições financeiras, mercadológicas e, principalmente, tecnológicas.

\subsection{A primeira tentativa de estabelecimento de uma política industrial e tecnológica no Brasil: O Modelo de Substituição de Importações (MSI)}

O modelo de substituição de importações, que se implantava no Governo J.K. no final dos anos 50 (Plano de Metas e os 50 anos em 5), tinha como propósito fundamental um crescimento industrial acelerado e fortemente apoiado na importação de tecnologia. Identificava que este padrão de industrialização já se fazia em plena fase do capitalismo monopolista mundial, onde se destacava a necessidade da construção de grandes plantas industriais, de empresas com estruturas de mercado oligopolizadas, e apoiadas em unidades fabris com grande densidade de capital, o que acarretava uma baixa massa de salários por unidade produzida. Nesse período, foi tomada uma série de medidas, tais como: a criação da Petrobrás (1953), estabelecendo o monopólio estatal do petróleo; criação do então Banco Nacional de Desenvolvimento Econômico (BNDE), que tinha a função primordial de apoiar a ampliação da infra-estrutura de transportes e energia; a instrução $\mathrm{n}^{\circ} 113$ (1955) da SUMOC, que possibilitou às empresas estrangeiras aqui sediadas importarem máquinas e equipamentos sem cobertura cambial. Todas essas medidas, além de outras, constituíram-se nos principais fatores do desenvolvimento capitalista no Brasil. Desta forma estavam lançadas as bases para o crescimento acelerado da economia brasileira, tendo como suporte financeiro o tripé formado pelo capital estrangeiro, pelo Estado, e, em menor escala, pelo capital privado nacional. Era evidente neste momento da história brasileira o fato de que as pequenas e médias empresas não faziam parte das prioridades em termos de políticas públicas.

Sob tal contexto de auge econômico, a facilidade com que os fluxos do comércio internacional foram dinamizados provocou um boom de importação de máquinas e equipamentos de toda espécie, o que possibilitou um enorme salto qualitativo e uma expansão considerável das indústrias básicas como a siderúrgica, química pesada e a de máquinas-ferramenta, dentre outras.

A implantação da indústria automobilística significou um marco de todas essas transformações estruturais; a relevância deste setor para o conjunto da economia brasileira traduzia-se pelo fato de que, por um lado, o seu produto se constituía no principal símbolo da vida moderna e, por outro, pela série de investimentos derivados desta indústria (RATTNER, 1988).

O desenvolvimento de todo o sistema de transporte rodoviário (construção das auto-estradas, pavimentação das vias públicas urbanas, etc.) e a expansão de um conjunto enorme de outros segmentos industriais, responsáveis pela oferta de todos os insumos necessários à fabricação do 
automóvel (borracha, pneus, vidro, aço, etc.), e de todo um conjunto de pequenas e médias empresas de auto-peças compuseram-se em fatores primordiais do processo de desenvolvimento industrial que se iniciava no Brasil ( SINGER, 1986).

\subsection{Medidas de política industrial sob o Regime Militar}

$\mathrm{Na}$ década de 60, sob a égide do governo militar, o Plano de Ação do Governo (PAEG) procurava enfatizar a importância do desenvolvimento tecnológico, por meio de medidas concretas, como a criação do FUNTEC (Fundo de Desenvolvimento Técnico-Científico, em 1964), cujo objetivo primordial era a formação de tecnólogos voltados para os segmentos industriais definidos como prioritários nos programas de financiamento do então BNDE. Estes planos e programas, apesar de destacarem o papel estratégico da ciência e da tecnologia (C\&T) para o desenvolvimento industrial e econômico do país, tratavam destas questões de uma forma muito vaga, sem traçar objetivos mais específicos, nem tão pouco criar instrumentos eficazes para a implementação de medidas concretas voltadas para uma efetiva política industrial. Àquela época, também, não se destacava qualquer iniciativa mais sistemática e objetiva no sentido da promoção de PMEs operando em redes de cooperação ou em cadeias produtivas.

\subsection{Os Planos de Desenvolvimento Econômico (PNDs) e a política industrial nos anos do Milagre Econômico}

Já no início da década de 70, sob um contexto de grande euforia e prosperidade econômica (época do milagre econômico), foi decretado o I PND - Plano Nacional de Desenvolvimento e, a partir deste plano, o I Plano Básico de Desenvolvimento Científico e Tecnológico - I PBDCT, que apresentava objetivos mais claros em termos de tecnologia aplicada à indústria, principalmente nos setores considerados de tecnologia de ponta, como a aeronáutica, a química e a eletrônica, em particular a de computadores. Posteriormente, no de 1976 a 1979 foi decretado o II PND juntamente com o II PBDCT, que propunha como prioritária, em termos de política tecnológica, a concessão de incentivos para as áreas de: energia elétrica, petróleo, fontes e formas não convencionais de energia (solar, gaseificada de carvão, biodigestores, dentre outras), transporte (principalmente urbanos) e comunicações, serviços postais etc. Fica clara, a partir destes objetivos, a preocupação maior com a questão da energia, provocada pelo primeiro choque do petróleo ocorrido em 1974.

Em síntese, o que se buscava naqueles vários planos e programas de desenvolvimento industrial e tecnológico era o fortalecimento da indústria nacional, por meio de uma política de substituição de importações e de uma política voltada à promoção de uma capacidade científica e 
tecnológica (que se evidência, por exemplo, na criação e/ ou fortalecimento de vários órgãos e instituições de fomento à pesquisa, como o CNPq e a FINEP).

Foi um período marcado pela intensificação do processo de concentração industrial, com a implantação de grandes plantas industriais, com estruturas organizacionais muito verticalizadas. De maneira geral, as pequenas e médias empresas cresciam ao redor dos principais complexos industriais, particularmente no setor de autopeças, sem se constituírem, porém, em maiores preocupações em termos de políticas industriais.

\subsection{A crise econômica e a ausência de política industrial na "década perdida" (anos 80)}

Conseqüência direta da situação de crise que marcou o início da década de 80 (stagflação e o agravamento do processo de endividamento externo), toda a política macroeconômica, em geral, e a política industrial e tecnológica, em particular, tiveram que ser profundamente alteradas, tendo em vista o objetivo maior imposto pelos órgãos financeiros internacionais (Fundo Monetário Internacional, especialmente), que consistia em gerar, constantemente, superávits na balança comercial, a fim de remunerar os serviços da dívida externa. A decorrência imediata desta nova política foi uma queda acentuada nos níveis de investimento no setor produtivo da economia, o que acarretou, por seu turno, uma aceleração do processo de obsolescência tecnológica em vários setores da nossa indústria, além da não realização dos objetivos inicialmente previstos, no sentido de um maior domínio e capacitação tecnológica em setores estratégicos.

A necessidade de geração constante de superávits comerciais e da reorientação do sistema produtivo trouxe implicações diretas sobre o conjunto da economia brasileira, destacando-se, dentre elas, a retração do mercado interno, por meio do rebaixamento do poder de compra dos salários, e a intensificação da exportação de manufaturados. Os efeitos desta reorientação estratégica se fizeram sentir de forma diferenciada nos diversos setores da nossa indústria.

Os projetos de substituição de importações implantados sob a diretriz do II PND atenuaram, de certa forma, os efeitos negativos da política econômica recessiva, na medida em que tais projetos passaram a uma fase de maturação. Porém, o fator que mais contribuiu para amenizar a forte queda na produção industrial foi o crescimento daqueles setores que, por possuírem maior grau de adaptabilidade, direcionaram parte de sua produção para o mercado externo.

A conseqüência imediata destas distorções setoriais traduziu-se por uma generalização da capacidade ociosa na indústria, no final do período recessivo. Apenas em alguns setores ligados às exportações, como a indústria produtora de bens intermediários, ocorreu até uma certa redução do grau de ociosidade de suas instalações. Por outro lado, o setor de bens de capital sob encomenda, 
por exemplo, que está voltado tradicionalmente para o mercado interno, encontrava-se em meados dos anos 80 com 3/5 de sua capacidade produtiva ociosa (SINGER, 1986).

Do ponto de vista tecnológico, se a indústria brasileira estava aquém dos padrões internacionais no início do período recessivo (80-83), as dificuldades nos anos mais recentes se acentuaram de forma significativa. Particularmente para o segmento das PMEs, foi um período extremamente difícil, dado que a retração da demanda nos setores-chave da economia provocou a falência de um sem-número de pequenas empresas que, na maioria dos casos, atuavam como fornecedoras de peças, componentes e demais insumos para as grandes empresas.

Em síntese, os anos 80 foram marcados por uma profunda crise fiscal e financeira, que trouxe como conseqüência para o Estado brasileiro pouca contribuição tributária e grandes gastos financeiros. Para a realidade das PMEs, em particular, a situação foi dramática: sem reforma fiscal e controle do pagamento de impostos, cresceu a sonegação e o valor dos impostos nas PMEs.

\subsection{A "Nova Política Industrial" no final dos anos 80}

A profunda crise econômica que marcou praticamente toda a década de 80 , como apresentada anteriormente, provocou uma séria desarticulação na estrutura industrial brasileira. Em vários setores importantes da indústria ocorreu um processo de obsolescência tecnológica, acarretando um sucateamento do parque industrial, tendo em vista a emergência dos novos padrões de produção e da divisão internacional do trabalho, que já se faziam presentes na época.

Vários setores e ramos da atividade industrial, principalmente aqueles relativos às tecnologias de ponta (microeletrônica/ informática/ automação, biotecnologia, química fina e mecânica de precisão), tinham sua dinâmica definida a partir de padrões globais de desempenho e qualidade.

Sob o novo paradigma tecnológico baseado na microeletrônica, predominavam empresas com plantas fabris menores (estruturas enxutas) e com maior flexibilidade em seus processos de produção, tendo em vista o rápido atendimento da demanda em mercados cada vez mais dinâmicos e integrados em nível mundial. Tais empresas passaram a apresentar, também, um novo conceito de eficiência organizacional, predominando a integração das várias funções e áreas por meio de um amplo sistema de informações, agilizando toda a comunicação interna e externa à empresa.

Em alguns setores de nossa indústria, como é o caso do metal-mecânico, a utilização das modernas máquinas e equipamentos acionados automaticamente por meio de dispositivos microeletrônicos (MFCN, CAD/ CAM, SFM, robôs industriais e outros) tornou-se mais freqüente. Tais inovações nos processos produtivos ocorreram com maior intensidade nas empresas ligadas ao complexo automobilístico (montadoras e fabricantes de autopeças) e em algumas empresas 
produtoras de máquinas-ferramenta e equipamentos sob encomenda. Porém, o ritmo de difusão destas novas tecnologias é, ainda hoje, muito incipiente, se comparado aos padrões da indústria mundial (AMATO NETO e FLEURY, 1989).

\subsection{Globalização, liberalizacão e desindustrialização: a economia brasileira nos anos 90}

Os anos 90 foram marcados por uma profunda mudança nos rumos da economia brasileira, com significativas implicações sobre toda a sua estrutura e dinâmica industrial. O governo Collor, sob a alegação de provocar uma rápida modernização de todo o parque industrial brasileiro, adotou um conjunto de medidas de médio e longo prazos, que poderiam ser sintetizadas como o fim do modelo de substituição de importações. Sob a inspiração neoliberal, aquele governo provocou uma ampla e radical abertura de mercado para os mais variados tipos de produtos importados. Os principais instrumentos de política macroeconômica utilizados naquele momento foram: redução das alíquotas de importações, desregulamentação do Estado e uma aceleração no programa de privatizações das empresas estatais.

Por outro lado, ainda, a tradicional prática de subsídios, principalmente para as exportações, foi totalmente suprimida; as únicas exceções restringiam-se aos setores considerados tecnologicamente estratégicos, como o da microeletrônica, ainda que a política de reserva de mercados para a informática, também já apresentasse data para se extinguir (outubro de 1992).

No início daquele governo, havia, também, a intenção de promover um novo ciclo de desenvolvimento econômico na constituição de um banco de financiamento para as exportações e de elevados investimentos na infra-estrutura, particularmente na modernização dos principais portos brasileiros.

Especificamente do ponto de vista da política industrial e tecnológica, destacam-se algumas idéias básicas contidas na estratégia de governo (1990-94), chamada de Política de Integração Competitiva (VELLOSO, 1992):

a) exploração da eletrônica e informática, em suas interfaces com a mecânica, a química fina, a utilização de novos materiais e a biotecnologia, gerando vantagens comparativas dinâmicas do país ainda não destacadas;

b) fortalecimento da competitividade nacional, em nível interno e externo, realizando o desenvolvimento tecnológico e de management, com enfoque macroeconômico.

Tal política destacava o fato de que o padrão tecnológico adotado, com suas características de flexibilidade e integração, poderia ser aplicado de forma genérica, em todas as atividades industriais, mesmo aquelas que não eram em massa (VELLOSO, 1992). Há que se ressaltar também a menção especial feita às novas técnicas de organização da produção (a grande maioria delas de 
origem japonesa) na busca de maiores ganhos de eficiência produtiva e de produtos de melhor qualidade.

Já o governo Itamar, que sucedeu o de Collor após o seu impeachment, deu continuidade à política de abertura de mercado, tendo em vista aumentar o nível de competição na economia brasileira como um todo, a partir da entrada indiscriminada de produtos importados, vindos principalmente dos países do leste asiático. Tal política visava, dentre outros, o objetivo de conter o processo inflacionário, combatendo setores oligopolizados e procurando romper com as tradicionais estruturas corporativas predominantes em vários setores da indústria nacional, que, acostumados a uma certa reserva generalizada de mercado (ainda que não institucionalizada para muitos setores), detinham poderes de práticas abusivas de preços.

Pode-se afirmar, em síntese, que este conjunto de medidas associado às iniciativas específicas de estímulos à modernização e reestruturação no âmbito das empresas (Programa Brasileiro de Qualidade e Produtividade- P.B.Q.P.) provocou, de fato, uma profunda mudança na estrutura industrial do país. Essas medidas também “contribuíram para modificar as formas de interação entre estado e os atores sociais na formulação políticas industriais" (MEYER-STAMER, 1997, p.239). Porém, este processo de mudanças, se por um lado estimulou as empresas a buscarem maior poder de competitividade a nível internacional, acabou por decretar a falência e o desaparecimento de inúmeras empresas, principalmente as de pequeno e médio portes, que se viram impossibilitadas de realizar mudanças radicais a curto prazo.

O complexo da indústria automobilística, por exemplo, passou por um processo de profundas alterações em sua estrutura, ao longo da primeira metade desta década. Do lado das montadoras de autoveículos, iniciou-se um processo de novos investimentos diretos, tanto na ampliação e modernização das plantas já existentes, como na instalação de novas plantas industriais, tanto por parte de companhias que já operavam no Brasil (Volkswagen, Ford, General Motors, Fiat), quanto de outras companhias européias e asiáticas (Renaut, Mercedes-Benz, Toyota, Honda, entre outras). Destaque-se, ainda, que aquele processo de modernização das plantas industriais inclui também as novas formas de organização da produção e de relações entre a montadora e as fornecedoras de autopeças, tais como aquelas referentes aos conceitos de Consórcio Modular e de Condomínio Industrial, onde as fornecedoras de conjunto de peças mais complexos (os chamados sistemistas) estão operando dentro da própria planta da empresa-mãe (montadora).

A partir de 1993 e, principalmente após julho de 1994, com a decretação do Plano Real, o setor ganhou fortes estímulos para aumentar a produção, atingindo em 1994 o maior volume de autoveículos produzidos ao longo de toda a história da indústria automotiva no Brasil até aquele momento. Já do lado das empresas de autopeças ocorreu uma profunda mudança no perfil de sua estrutura, com uma aceleração rápida do processo de internacionalização desta indústria, com a 
concentração do mercado produtor, por meio de vários movimentos de fusões e, principalmente, de aquisições de empresas de capital nacional por parte de grandes grupos internacionais (casos típicos e ilustrativos de aquisições de importantes e tradicionais empresas do setor de autopeças foram: Cofap, Metal-Leve e Freios Varga). Este importante segmento da indústria, onde a participação das pequenas e médias empresas foi, até bem recentemente, bastante significativa, defrontou-se com uma profunda transformação, em função da entrada de grandes empresas de capital estrangeiro, muitas delas vinculadas às montadoras em seus respectivos países de origem.

Em decorrência desta reorientação estratégica do mercado, começaram a ganhar força na empresas de autopeças as práticas gerenciais inspiradas na idéia qualidade total, e mais recentemente (a partir dos primeiros anos da década de 90), intensificaram-se os esforços pela certificação dos Sistemas de Qualidade - pelas normas da série ISO 9.000. Estas últimas ocorreram por imposição das empresas montadoras, que já estas estabeleceram prazos para que seus fornecedores sejam qualificados (AMATO NETO, 2000).

Contudo, outros setores industriais tradicionalmente importantes na economia brasileira tiveram suas operações praticamente paralisadas ao longo da década de 90, como a indústria de máquinas e bens de capital em geral, a indústria de brinquedos, a indústria eletro-eletrônica, entre outras, enquanto que outros setores reduziram drasticamente sua produção diante da invasão de produtos similares importados (casos típicos da indústria de calçados e do setor têxtil).

Ao longo deste processo de desindustrialização, constatou-se, porém, algumas exceções: a indústria aeronáutica brasileira, representada basicamente pela Embraer e sua rede de fornecedores, vem apresentando um notável desempenho ao longo dos últimos anos, conseguindo inclusive recuperar importantes posições relativas em mercados internacionais.

Por outro lado, também tem-se que a partir da decretação do Plano Real, no governo Fernando Henrique Cardoso, a estabilização econômica trouxe consigo novos estímulos à alguns setores da indústria, principalmente àqueles relacionados aos produtores de bens de consumo corrente.

\subsection{A política industrial no governo "Lula": setores prioritários e estímulos às MPMEs}

Decretada no início de 2004, a "Política Industrial, Tecnológica e de Comércio Exterior" do governo Lula consiste em um plano de ação que tem por finalidade estimular o aumento da eficiência produtiva, incentivando as empresas brasileiras a inovarem em seus produtos e processos, visando, desta forma, aumentar sua capacidade de inserção competitiva nos mercados externos mais dinâmicos. Cabe salientar que "Política Industrial, Tecnológica e de Comércio Exterior" não é uma iniciativa isolada. Ela faz parte de um conjunto de ações que compõem a estratégia de desenvolvimento apresentada no documento Orientação Estratégica de Governo: Crescimento 
Sustentável, Emprego e Inclusão Social” (MDIC, 2006). Tal política, deve estar, portanto, articulada com os novos planos de investimentos na melhoria da infra-estrutura (parte integrante, a propósito, do conjunto de medidas previstas no PPA), assim como com as estratégias e projetos de desenvolvimento regional.

Em termos de setores prioritários para o desenvolvimento tecnológico e industrial foram eleitos os seguintes: indústria de bens de capital; indústria de fármacos; software e a indústria de semicondutores. Tais setores representam, de fato, as áreas de fronteira do conhecimento científico e tecnológico e se constituem nas bases do desenvolvimento auto-sustentável das nações neste século.

Particularmente, no que diz respeito às pequenas e médias empresas, a nova política industrial estabelece um conjunto de medidas para o fortalecimento e aumento do poder competitivo desata categoria de empresas. São estas:

Programa de Extensão Industrial Exportadora: Trata-se de uma iniciativa de consultoria pública que visa, basicamente, capacitar as PMEs para que possam tratar suas deficiências técnica e gerenciais, a fim de aumentar seu poder de competitividade no mercado externo. A meta de tal programa é atender cerca de 100 mil MPMEs inseridas em aglomerações ou nos chamados arranjos produtivos locais (APLs). Tal programa deverá ser executado pelo Ministério do Desenvolvimento Industrial e de Comércio Exterior (MDIC).

Certificação de Consórcio, Bônus de Metrologia e de Certificação: Consiste em um programa de apoio à certificação das PMEs, priorizando alguns setores em que o Brasil já apresenta uma indústria competitiva, e nos quais a obtenção de certificação poderá se constituir em um diferencial competitivo, tais como: madeira, indústria moveleira e de calçados.Participarão deste programa as seguintes instituições: INMETRO, Sebrae e MBC.

Programa de Inovação Tecnológica em Arranjos Produtivos Locais (APLs): Tem por objetivo apoiar cerca de 50 APLs em todo o país, no desenvolvimento de projetos (Finep) que priorizem a solução de "gargalos tecnológicos" nas PMEs.

Programa de Promoção Comercial no Mercado Interno: Como o próprio nome expressa, visa desenvolver maior capacitação comercial e mercadológica das PMEs, focalizando a promoção de mercadorias produzidas pela PMEs, incluindo a participação em feiras. (MDIC, 2006; SEBRAE, 2003). 


\section{Políticas públicas de estímulo à cooperação produtiva entre as MPMEs: Novas perspectivas}

Novas formas de políticas públicas orientadas no sentido de maior cooperação e integração entre as PMEs tem sido desenvolvida no Brasil com maior intensidade a partir do início dos anos 90. Algumas destas políticas relacionam-se tanto com estratégias mais amplas do próprio governo federal, como com iniciativas de governos locais e regionais, tais como aquelas dirigidas ao fortalecimento dos chamados clusters regionais ou arranjos produtivos locais (APLs), que são aglomerações de empresas pertencentes a uma mesma cadeia produtiva localizadas em uma mesma região. Tais políticas estão em sintonia como os novos padrões de localização de investimentos, que buscam romper com as tradicionais práticas baseadas em critérios convencionais das vantagens competitivas tradicionais. Neste novo contexto buscam-se vantagens competitivas dinâmicas, tais como: a existência de uma infra-estrutura local adequada, proximidade com centros de pesquisa e desenvolvimento, oferta de mão-de-obra qualificada, acesso aos modernos meios de transporte e de comunicação e outras.

De fato, as políticas públicas orientadas no sentido do fortalecimento das aglomerações de MPMEs mostram-se imprescindíveis aos países em desenvolvimento como o Brasil, onde 52,8\% da força de trabalho estão nas micro e pequenas empresas, mas que por sua vez apresentam uma taxa de mortalidade de 39\% no primeiro ano de atividade (SEBRAE, 2003). Especificamente no caso brasileiro, ainda que não se encontrem no mesmo nível de desenvolvimento dos clássicos distritos industriais como os da Terceira Itália, pode-se identificar alguns exemplos destas aglomerações de relativo sucesso: Vale dos Sinos, produtor de calçados no Rio Grande do Sul, o de cerâmica de revestimento no Estado de Santa Catarina, o pólo fabril de calçados infantis de Birigui/SP, o de moda íntima de Nova Friburgo na região serrana do Rio de Janeiro, entre outras. Segundo Puga (2003) já foram identificadas 193 clusters no Brasil, envolvendo cerca de 77.000 empresas e 680.000 empregados. Deste total, 42 clusters localizam-se no estado de São Paulo, compreendendo 15.000 empresas e 140.000 empregados.

Além deste tipo de orientação estratégica de fortalecimentos dos clusters ou arranjos produtivos locais ( APLs), as políticas públicas desenvolvidas na história recente do Brasil pós-90, também buscam valorizar a figura dos parques tecnológicos e das incubadoras de empresas, principalmente das PMEs de base tecnológica. Em 1986, quando começaram a ser formalmente implantadas, existiam 42 incubadoras de empresas no Brasil. Atualmente são 339 incubadoras envolvendo cerca de 5.600 empresas (incubadas, associadas e graduadas), segundo dados da ANPROTEC (2006), com grande predominância nas regiões sul (123) e sudeste (120). Somente nos estado de São Paulo existem mais de 35 projetos de instalação de novas incubadoras. Fato interessante a se destacar diz respeito que deste total de incubadoras no Brasil, $40 \%$ delas são do 
tipo incubadoras de empresas de base tecnológica. A título de ilustração cabe destacar alguns casos: o Parque de Alta Tecnologia de São Carlos, que já incubou dezenas de pequenas empresas dos setores de novos materiais, software, microeletrônica e telecomunicações; o Porto Digital em Recife /PE, importante pólo produtor e exportador de software. Além destes só no interior do campus da própria Universidade de São Paulo na cidade de São Paulo foram criadas duas incubadoras: O Centro Incubador de Empresas Tecnológicas (CIETEC), criado em abril de 1998, e que já conta com cerca de 15 empresas atuando nas áreas de: instrumentação, biotecnologia, laser, aplicações técnicas nucleares, informática, meio ambiente, entre outras.; e a Incubadora Tecnológica de Cooperativas Populares (ITCP/USP), criada em agosto de 1998, destinada, basicamente, a fomentar a formação de cooperativas e auxiliá-las no processo de gestão e inserção de seus produtos ou serviços no mercado.

Atualmente, os estímulos à formação e desenvolvimento das incubadoras de PMEs provêm de diversas fontes As instituições científicas de ensino e pesquisa, os governos estaduais, as prefeituras e mesmo diversas entidades privadas, como a Federação das Indústrias do Estado de São Paulo (FIESP), têm destinado recursos para incubadoras brasileiras. O estímulo do Sistema SEBRAE Nacional e dos SEBRAEs estaduais também têm sido significativo. Destaque-se, também, os programas PIPE (Inovação Tecnológica em Pequenas Empresas) e PITE (Parceria para Inovação Tecnológica) da Fapesp, destinados exclusivamente à transferência de tecnologia das universidades e institutos/centros de pesquisa e ao financiamento de projetos de produtos e processos que tenham potencial de gerar novas pequenas empresas de base tecnológica.

Por outro lado, ainda, faz-se necessário salientar o importante papel realizado pela Associação Brasileira de Pólos, Parques e Incubadoras (ANPROTEC). Fundada em 1987, a entidade reúne os parques tecnológicos e as incubadoras de empresas, facilitando o intercâmbio e a troca de experiência entre eles (PEREIRA e BERMÚDEZ, citados por PALADINO e MEDEIROS, 1997). Neste sentido o Ministério da Ciência e Tecnologia criou, recentemente, o Programa Nacional de Apoio a Incubadora de Empresas (PNI), que tem por objetivo principal estimular o desenvolvimento de novas tecnologias de produtos, processos e serviços de alto valor agregado, como um dos principais mecanismos para elevar a participação de MPMEs no mercado internacional. São as seguintes entidades que participam deste Programa (PNI): Ministério da Ciência e Tecnologia, por meio da Secretaria de Desenvolvimento Tecnológico (SETEC) e das agências de fomento: Conselho Nacional de Desenvolvimento Científico e Tecnológico (CNPq) e Financiadora de Estudos e Projetos (FINEP), Ministério da Indústria, Comércio e Turismo (MICT), por meio da Secretaria de Política Industrial (SPI) e da Secretaria de Tecnologia Industrial (STI), Banco Nordeste, Serviço Brasileiro de Apoio às Micro e Pequenas Empresas (SEBRAE), 
Associação Nacional de Entidades Promotoras de Empreendimentos Inovadores (ANPROTEC), Serviço Nacional de Aprendizagem Industrial (SENAI) e Instituto Euvaldo Lodi (IEL).

Outras instituições (bancos regionais e comerciais, cooperativas de crédito, associações empresariais e outras) começaram a desenvolver algum tipo de apoio às pequenas empresas, principalmente em termos de financiamento e crédito. Sabe-se que, tradicionalmente, as MPMEs apresentam uma série de dificuldades para oferecerem garantias para os bancos e outras instituições de crédito, o que dificulta seu acesso a financiamentos. Neste sentido é que tais instituições, como o SEBRAE, buscam desenvolver programas de apoio à micro e pequena empresa, voltado à oferta de créditos com o objetivo de aumentar a qualidade de bens e serviços, a produtividade e a competitividade das micro e pequenas empresas.

Quanto às redes de apoio à gestão e capacitação empresarial, destacam-se alguns programas voltados à modernização gerencial das PMEs, como o programa de qualidade total e o de formação de Recursos Humanos, promovidos pelo SENAI e o SENAC, por meio de convênios com o SEBRAE. Há também a iniciativa conjunta de várias instituições (SEBRAE, SENAI, CNI e USP) no sentido de difundir informação tecnológica junto às PMEs.

\section{Conclusões}

As análises relativas à atuação do Estado brasileiro na formulação e condução de políticas públicas destinadas ao estimulo e fortalecimento das MPMEs, ao longo das últimas décadas, revela que muito pouco se fez de concreto do ponto de vista de medidas objetivas e de práticas de médio e longo prazos. Quanto às possibilidades contemporâneas para o desenvolvimento das PMEs no Brasil, destaca-se a busca por uma maior cooperação interorganizacional e por redes entre empresas, instituições de ensino, pesquisa e desenvolvimento, entidades de classe e outras. É importante salientar, entretanto, as inúmeras dificuldades e problemas, tanto de ordem financeira, como técnico-organizacional e gerencial, encontrados pelas PMEs, na busca para se tornarem viáveis e competitivas, diante da tendência de globalização das economias nacionais e regionais, principamente no caso de empresas que atuam de forma isolada em seus respectivos mercados.

Todavia, tais dificuldades poderão ser mitigadas através de políticas públicas voltadas à promoção das PMEs mais consistentes e de longo prazo, tais como, por exemplo, incentivando estas empresas de menor porte à se associarem em organizações na forma de sistemas cooperativos (como guarda-chuvas organizacionais). Tais sistemas devem privilegiar ações que forneçam às empresas serviços compartilhados de compras, marketing, laboratórios de pesquisa (para testes, ensaios e de metrologia industrial, por exemplo), orientações quanto à exportação, mecanismos de financiamento e de concessão de crédito, privilegiem as ações de cooperação inter-empresas e 
formas de atração de capital de risco (venture capital), e, até mesmo, locais para a implantação de uma planta piloto (como as chamadas incubadoras industriais).

Por fim, porém não menos importante, espera-se, também, que prevaleçam mecanismos voltados à efetiva participação dos agentes envolvidos em uma dada rede de cooperação ou um arranjo produtivo local de MPMEs, e que tais agentes desenvolvam ações conjuntas baseadas em confiança mútua, entendendo que esta condição constitui-se em fator decisivo de sucesso em qualquer ação coletiva.

\begin{abstract}
The objective of this article is to accomplish a critical revision of the several proposals of industrial and technological politics, developed during the last yaers in the Brazilian economy and its possible impacts in favor of the development of the small and medium companies (SMEs), emphasizing the aspect of the relationship between the goverment and the productive sector. The study highlights the initiatives of productive cooperation as an emergent form of promotion of such politics. The methodological approach is based on a literature revision with exploratory and qualitative character.
\end{abstract}

Key-words: industrial politics, Brazilian economy, small and medium companies, productive cooperation.

\title{
Referências
}

AMATO NETO, J. Redes de cooperação produtiva e clusters regionais: oportunidades para as pequenas e médias empresas. São Paulo: Atlas, 2000.

AMATO NETO, J.; FLEURY, A.C.C. Política de industrialização e setores prioritários. In: SIMPÓSIO EPUSP SOBRE MODERNIZAÇÃO TECNOLÓGICA E POLÍTICA INDUSTRIAL, 1., 1989, São Paulo. Anais. São Paulo: NEP/ EPUSP, 1989. p. 15-70.

ANPROTEC (ASSOCIAÇÃO NACIONAL DE ENTIDADES PROMOTORAS DE EMPREENDIMENTOS INOVADORES). Panorama das Incubadoras e Parques Tecnológicos. Disponível em: http://www.anprotec.org.br/panorama.htm . Acesso em 20 ago. 2006.

BIANCHI, G. M. Terceirização no Brasil: uma análise do novo papel desempenhado por empresas, trabalhadores e Estado. 1995. Dissertação (Mestrado em Engenharia [Engenharia de Produção]) - Escola Politécnica, Universidade de São Paulo, São Paulo.

CASAROTTO FILHO, N.; PIRES, L.H. Redes de pequenas e médias empresas e desenvolvimento local: estratégias para a conquista de competitividade global com base na experiência italiana. São Paulo: Atlas, 1999.

MDIC - MINISTÉRIO DO DESENVOLVIMENTO INDUSTRIAL E DE COMÉRCIO EXTERIOR. Política tecnológica e de comércio exterior. Brasília: MDIC. Disponível em:

http://www.desenvolvimento.gov.br/sitio/ascom/ascom/polindteccomexterior.php . Acesso em 29 jul. 2006.

MEYER-STAMER, J. Technology, competitiveness and radical policy change. London: Frank Cass \&Co., 1997.

PALADINO, G.G.; MEDEIROS, L.A. Parques tecnológicos e meio urbano: artigos e debates. ANPROTEC, 1997.

PUGA, F. Alternativas de apoio a MPMEs localizadas em arranjos produtivos locais. Texto para discussão 99 , Brasília, 2003. 
RATTNER, H. (Org.). Pequenas Empresas - o comportamento empresarial na acumulação e na luta pela sobrevivência. São Paulo: Brasiliense, 1985.

Política industrial: um projeto social. São Paulo: Brasiliense, 1988.

SEBRAE (SERVIÇO BRASILEIRO DE APOIO ÀS MICRO E PEQUENAS EMPRESAS). Outras estatísticas sobre

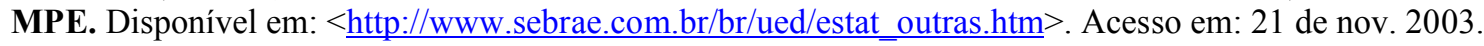

SINGER, P. Interpretação do Brasil: uma experiência histórica de desenvolvimento. In: FAUSTO, Boris (dir.). História Geral da Civilização Brasileira: III. O Brasil Republicano - economia e cultura (1930-1964). 2 ed. São Paulo: Difel, 1986.

VELLOSO, J.P. Estratégia industrial e retomada do desenvolvimento. Rio de Janeiro: José Olímpio, 1992.

\section{Dados do autor:}

Nome completo: João Amato Neto

Filiação institucional: Escola Politécnica da Universidade de São Paulo (EPUSP)

Departamento: Engenharia de Produção

Função ou cargo ocupado: Professor associado (livre-docente) e Coordenador do Núcleo de Pesquisa "Redes de Cooperação e Gestão do Conhecimento (REDECOOP)"

Endereço: Av. Prof. Almeida Prado, 128 - trav. 2 - 05508-900 - São Paulo-SP - Brasil

Telefones para contato: (11) 3091-5363 - Ramal: 452 / (11) 9934-4783

e-mail: amato@usp.br

Recebido para publicação em: 01/02/2007

Aceito para publicação em: 08/03/2007 